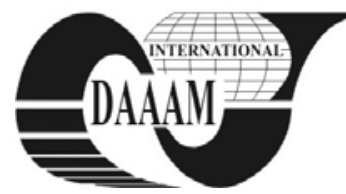

\title{
SERVICE LIFE OF UNIVERSAL GEAR REDUCERS
}

\author{
KUZMANOVIC, S[inisa] B[ogdan] \& RACKOV, M[ilan] J[ovan]
}

\begin{abstract}
This paper analyses problematic of service life and lifetime of universal gear reducers, with particular attention on their calculation. When designing universal gear units, designers neither know the place of reducer application, nor the exploitation regimes and therefore they define service life which will enable gear reducer achieve projected lifetime with all exploitation conditions. This paper emphasises the basic principles of defining service life of gear reducer, because it is crucial for bringing final decision about gear reducer selection. On the basis of the performed analysis it follows that the existing approach, the gearbox are designed for light regime of exploitation and its loading capacity is reduced by means of service factor for moderate or heavy shocks, is fully justified. However, there is no any justification that values of service life and lifetime are not shown in the catalogues of gear reducers, since they are important factors that should certainly affect the placement on the market of the gear reducers.
\end{abstract}

Key words: service life, lifetime, gear reducer

\section{INTRODUCTION}

Today, most manufacturers of universal gear reducers (Nord, Lenze, Rossi, Siemens, Bonfiglioli, 2010) do not specify the service life of their gear units in their catalogues, because it is a very "flexible" and depends on the actual load and concrete gear ratio, i.e. on the rotating speed of certain bearings and gears (Ognjanović, 2000). In some cases this fact can be a great problem for designers who install universal gear units (Niemann et al., 2009), because they are neither able to determine their lifetime, nor the lifetime of the new designed machines in which they are installed.

\section{SERVICE LIFE AND LIFETIME}

Service life of gear reducer $\left(t_{s l}\right)$ defines overall time during which reducer can continually operate, at normal conditions and provide exploitation regime, without significant decreasing of its basic operating characteristics at economicaly reasonable maintenance price (Orlov, 1977) (Fig.1).

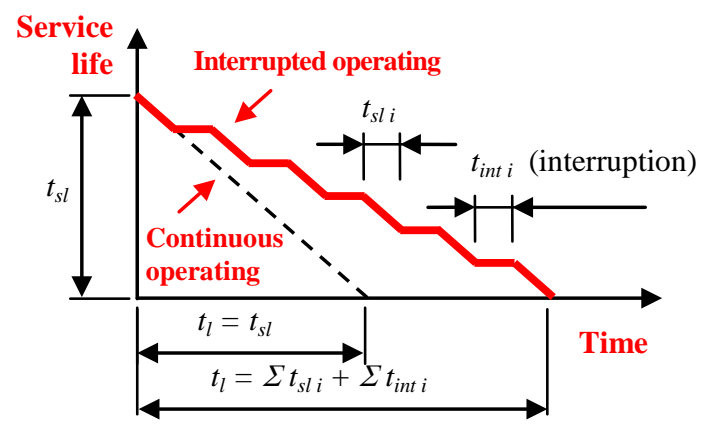

Fig. 1. Schematic review of service life $\left(t_{s l}\right)$ and lifetime of gear reducer $\left(t_{l}\right)$ in continuous operating and with interrupted operating
This period of time is usually called gearbox resource. In many cases reducer service life is represented indirectly, by overall performance of reducer in the machine in which it is installed. Service life, represented in that way, shows the number of operations or elementary tasks, that a machine can perform until it becomes worn out, i.e. until it requires reparation. For example, service life of agricultural machines is usually expressed by overall number of hectares of treated area, and service life of transport vehicles is expressed by overall number of ranged kilometres, etc.

Lifetime of gearbox $\left(t_{l}\right)$ includes total time of gearbox operating with interruptions, usually in years, until its all resources are exploited (Fig.1). Lifetime depends only on projected service life of reducer (available gearbox resource) and the intensity of its use. Certainly, more intensive use and shorter service life result in reducing of gearbox lifetime, and vice versa. When all resources are exhausted, gear unit is being repaired, since it is adjusted for repairing. Thus, gearbox resources are restored (partially or even completely) and it can be reused. Of course, repairs can be done only several times, after which a new gear unit should be provided, not only because of its efficiency, but also because it is technically outdated. More accurate definition of lifetime, it distinguishes functional, technical, economic, ecological and fashion life. Also, projected and actual lifetime of gear reducer should be kept in mind.

Projected lifetime of gearbox $\left(t_{p l}\right)$ is calculated using formula

$$
t_{p p l}=\frac{t_{p o}}{365 \cdot 24 \cdot k_{e}}
$$

where:

$k_{e}$ - coefficient of gearbox engagement, calculated according to expression (Kuzmanović \& Rackov, 2010):

$$
k_{e}=k_{1} k_{2} k_{3} k_{4} k_{5} k_{6} k_{7}
$$

where: $k_{1}$ - coefficient of machine usage represents ratio of number of days in a year, when a machine can be used, and total number of days during the year; $k_{2}$ - coefficient of working days represents ratio of number of working days and total number of days during the year; $k_{3}$ - coefficient of shifts represents ratio of duration time of a shift in hours and total number of hours during a day; $k_{4}$ - coefficient of interruption due to repair represents ratio of gearbox operating time and total time of operating and interruption time for repairing; $k_{5}$ coefficient of machining time represents ratio of machining time and total machining and service time (time for regulation, serving and maintenance of machine where gearbox is installed); $k_{6}$ - coefficient of loadings represents ratio of effective operating time and total effective operating time and time when gear unit is not loaded (if it exists); $k_{7}$ - coefficient of unexpected interruption represents ratio of actual effective operating time and total actual effective operating time and gearbox interruption time caused by malfunctions that can be 
repaired immediately. Values of these coefficients should be carefully adopted, because they have great influence on accuracy of the final results.

Duration of gearbox lifetime is determined during construction process depending on the type and purpose of reducer. Certainly, duration of lifetime also depends on manufacturing method, storage, the conditions where the gearbox operates, reducer maintenance conditions, and on global technical level of exploitation. Of course, nothing of this is known in the process of design. Appropriate and careful usage of reducer, its qualified and quality maintenance, proper and regular prevention and overload avoidance can significantly increase lifetime of gearbox. However, lifetime depends on lifetime of its particular components, which are hard to harmonize, and also on their reliability, so that just an average lifetime can be defined for gear reducer.

However, actual lifetime of reducer $\left(t_{a l}\right)$ can significantly deviate from projected lifetime $\left(t_{p l}\right)$ depending on the conditions and methods of exploitation. Systematic overloading of gear unit, i.e. its operating with higher revolutions number or bigger loads, significantly reduces its lifetime, which can be presented by coefficient of operating regime $\left(k_{o}\right)$ that directly influences on actual lifetime

$$
t_{a l}=t_{p l} / k_{o}
$$

The value of this coefficient depends on the operating conditions and can be adopted as follows: for hard exploitation conditions $k_{o}=1.2$ to 1.5; for average exploitation conditions $k_{o}=1$; and for light exploitation conditions $k_{o}=0.7$ to 0.8 (Kuzmanović et al., 2009). Of course, these are just approximate values that can be used for rough calculations, and exact values can be obtained only by individual researching of conditions and exploitation regimes influences on service life of specific gearbox. For example, gear reducer that can be used during all year $\left(k_{1}=1\right)$, which is installed in a machine that works only five days in a week $\left(k_{2}=0.69\right)$, and which operates in one $\left(k_{3}=0.33\right)$, two $\left(k_{3}=0.67\right)$ or three shifts $\left(k_{3}=1\right)$, which works in a standard calendar regime $\left(k_{4}=0.95\right)$, and when the machine, where the gearbox is installed, requires certain manual adjustments $\left(k_{5}=0.95\right)$, when there is some operation without loading $\left(k_{6}=0.95\right)$ and when the gearbox is properly designed and when qualified personnel handle with the machine, so that unexpected interruption cannot appear $\left(k_{7}=\right.$ 1), it follows that coefficient of gearbox engagement (eq.2) $k_{e}=$ 0.195 (for work in one shift), or 0.39 (for work in two shifts) or 0.592 (for work in three shifts). On the basis of equations (1) and (3), it follows that actual lifetime (Tab.1) ranges in different intervals.

If it is assumed that the projected service life of gearbox is 10000 hours, it follows that actual lifetime, depending on exploitation regime (Tab.1), will be 3.9 years for work in one shift (hard regime) up to 8.36 years (light regime); for work in two shifts from 1.95 up to 4.18 years and for working in three shifts from 1.29 up to 2.73 years. This last is extremely short lifetime and therefore the gearbox loading should be limited (by means of service factor), so that the gearbox will achieve projected lifetime of 5 years. In the case the gearbox operates seven days a week; actual lifetime would be even shorter.

\begin{tabular}{|l|c|c|c|c|}
\hline \multirow{2}{*}{$\begin{array}{c}\text { Exploitation } \\
\text { regime }\end{array}$} & $\begin{array}{c}\text { Coefficient } \\
\text { of operating } \\
\text { regime, } k_{o}\end{array}$ & \multicolumn{3}{|c|}{$\begin{array}{c}\text { Actual lifetime of gearbox }\left(t_{a l}\right) \text { with } \\
\text { projected service life of } 10000 \text { hours, } \\
\text { expressed in years }\end{array}$} \\
\cline { 3 - 5 } & $\begin{array}{c}\text { work in one } \\
\text { shift }\end{array}$ & $\begin{array}{c}\text { work in two } \\
\text { shifts }\end{array}$ & $\begin{array}{c}\text { work in } \\
\text { three shifts }\end{array}$ \\
\hline Hard & $1.2-1.5$ & $4.87-3.9$ & $2.44-1.95$ & $1.61-1.29$ \\
\hline Average & 1 & 5.85 & 2.93 & 1.93 \\
\hline Light & $0.7-0.8$ & $8.36-7.31$ & $4.18-3.66$ & $2.73-2.41$ \\
\hline
\end{tabular}

Tab. 1. Actual lifetime of gearbox expressed in years (with projected service life of 10000 hours) depending on exploitation regime
Limiting the load $\left(T_{i}\right)$ can be done by service factor

$$
T_{2}=T_{2 \max } / f_{B}
$$

where: $T_{2}$ - output torque resulting from the installed motor power, $T_{2 \max }-$ maximum gearbox output torque, $f_{B}$ - service factor.

A value of service factor for universal gear reducer is adopted from the diagram or table. Its value directly influences the size of gear unit, so that for heavier operating condition a service factor is selected to adopt a larger (stronger) gearbox that will provide a longer lifetime, and so it will be able to achieve projected lifetime for hard exploitation regime, too. For the light exploitation condition lower value of the service factor is adopted and thus higher loading of reducer is allowed which evens the gearbox lifetime. The value of service factor also depends on classification of an operation (uniform operation, moderate or heavy shocks), daily operational time and the cycles per hour, and for exact selection it depends on cyclic duration factor ED per hour, temperature of an ambient and desired lifetime of reducer.

Today it is common to adopt the gearbox lifetime of 5 years and with that value to calculate the required service life for working in one shift. If it is assumed that the working week is 40 hours and there are 50 working weeks in a year, it follows that the service life amounts 5 years x 50 working weeks x 40 hours per week $=10000$ hours. Such service life provides 5 years lifetime for light exploitation conditions. In the case the reducer loading conditions are different (medium and heavy), the working is in multiple shifts and the reducer is subjected to a frequent shocks due to more starting cycles, it follows the service factor reduces its load capacity (eq.4), which provides reaching the projected lifetime of 5 years.

\section{CONCLUSION}

On the basis of the performed analysis it follows that the existing approach, the gearbox are designed for light regime of exploitation and its loading capacity is reduced by means of service factor for moderate or heavy shocks, is fully justified. However, there is no any justification that these values are not shown in the catalogues of gear reducers, since the service life is an important factor that should certainly affect the placement on the market of the gearbox. More accurate selection of gear reducers would be enabled by presenting the calculation procedure for the gearbox service life which all designers who use and install universal gear reducers would certainly welcome.

\section{REFERENCES}

Kuzmanović, S.; Rackov, M. \& Veres, M. (2009). Product Lifetime. Scientific Proceedings 2009, ISBN 978-80-2273326-7, Palcak, F. \& Horvat, M. (Ed.), pp. 135-144, Faculty of Mechanical Engineering, STU in Bratislava, Bratislava

Kuzmanović, S. \& Rackov, M. (2010). Factors That Influence on Product Lifetime, Annals Of the Faculty Of Engineering Hunedoara, Tome VIII, Fascicole 2, pp. 239-244, ISSN 1584-2665

Niemann, J.; Tichkiewitch, S. \& Westkamper, E. (2009). Design of Sustainable Product Life Cycles, Springer Verlag, ISBN 978-3-540-79081-5, Berlin, Heidelberg,

Ognjanović, M. (2000). Development and Design of Machines (in Serbian), Faculty of Mechanical Engineering, ISBN 978-86-7083-603-7, Belgrade

Orlov, P. I. (1977). Fundamentals of Machine Design, Mir, Mašinostroenie, ISBN 0714718637, Moscow

*** Catalogues: Nord G1000 (2010), Lenze L-force (02, 2010), Rossi ES07 (12, 2010), Siemens D87.1 (2010), Bonfiglioli (2010) 